\title{
Going greener: Synthesis of fully biobased unsaturated polyesters for styrene crosslinked resins with enhanced thermomechanical properties
}

\author{
C. S. M. F. Costa ${ }^{1,2}$, A. C. Fonseca ${ }^{2}$, J. Moniz ${ }^{1}$, M. Godinho ${ }^{1}$, J. F. J. Coelho ${ }^{2}$, A. C. Serra ${ }^{2}$ \\ ${ }^{1}$ Resiquímica - Resinas Químicas, S.A., Rua Francisco Lyon de Castro 28, 2725-397 Mem Martins, Portugal \\ ${ }^{2}$ CEMMPRE, Department of Chemical Engineering, University of Coimbra, Pólo II, Pinhal de Marrocos, 3030-790 \\ Coimbra, Portugal
}

Received 10 April 2017; accepted in revised form 11 June 2017

\begin{abstract}
The main goal of this work was the development of fully biobased unsaturated polyesters (UPs) that upon crosslinking with unsaturated monomers (UM) could lead to greener unsaturated polyester resins (UPRs) with similar thermomechanical properties to commercial fossil based UPR. After the successful synthesis of the biobased UPs, those were crosslinked with styrene (Sty), the most commonly used monomer, and the influence of the chemical structure of the UPs on the thermomechanical characteristics of UPRs were evaluated. The properties were compared with those of a commercial resin (Resipur $9837^{\circledR}$ ). The BioUPRs presented high gel contents and contact angles that are similar to the commercial resin. The thermomechanical properties were evaluated by dynamic mechanical thermal analysis (DMTA) and it was found that the UPR synthesized using propylene glycol (PG), succinic acid (SuAc) and itaconic acid (ItAc) presented very close thermomechanical properties compared to the commercial resin.
\end{abstract}

Keywords: thermosetting resins, biobased unsaturated polyester, thermomechanical properties

\section{Introduction}

Unsaturated polyester resins (UPRs) are currently one of the most important types of thermoset polymers in the industry. These polymers are well-known for their excellent balance between mechanical, electrical and chemical properties. They have found applications in diverse sectors, including: coatings, reinforcement materials in construction, marine and automotive industries [1-3]. The petroleum-based maleic anhydride (MA), phthalic anhydride ( $\mathrm{PhA})$ and $\mathrm{PG}$ are the most regularly employed monomers in the industrial synthesis of UPRs [4, 5]. However, the increasing environmental concerns, as well as the need to develop sustainable alternatives to fossil based monomers, have led to a remarkable interest in the development of biobased UPRs (BioUPRs). In the market, there are already a considerable number of available renewable monomers for the synthesis of UPs and UPRs [6-8] and, in the last years, some authors have focused their work on the development of UPRs partially based on these raw materials [4, 9-11]. The work of Gonçalves et al. [4] reports the preparation of UPRs for microstereo-thermal-lithography ( $\mu$ STL), with a biobased content between 24 and $47 \mathrm{wt} \%$. The UPs were prepared using some biobased monomers such as fumaric acid (FuAc), SuAc, adipic acid (AdAc), sebacic acid (SeAc) and PG. The obtained UPs were characterized by a good thermal stability and a glass transition temperature $\left(T_{\mathrm{g}}\right)$ that has shown to be dependent on the formulation compositions. In another study, Fonseca et al. [12] prepared UPRs with high biobased content

"Corresponding author, e-mail: anafs@eq.uc.pt C BME-PT 
using the biobased monomers FuAc, ItaAc, SeAc, PG, 1,3-propanediol (PDO) and isosorbide (Iso). After the crosslinking reaction of biobased UPs with 2-hydroxyethyl methacrylate (HEMA), the UPRs presented high gel content and good thermal stability. The thermomechanical properties of the resins revealed the presence of two main transitions, $\alpha$ and $\beta$, corresponding to the motion of different domains in the resins. Recently, Sousa et al. [13] developed UPRs based on 2,5-furandicarboxylic acid (FDCA), with a biobased content of $50 \mathrm{wt} \%$. The UPs were synthesized by bulk polycondensation between FDCA, SuAc, FuAc and PDO, with no catalyst or purification steps. The biobased UPs were crosslinked with HEMA, showing good thermal stability and high $T_{\mathrm{g}}$ values. Despite the relevance of these works in the development of BioUPRs, until now very few groups developed UPRs that comprised the use of monomers from renewable sources (with biobased content lower than $20 \mathrm{wt} \%$.) and compared their properties with a fossil based commercial UPR. Sadler and co-workers focused their work on the development of UPRs with Iso and compared their properties with two commercial resins, viz. Hexion $713-6150^{\circledR}$ and Viapal $450^{\circledR}[5,9]$. The developed Iso containing UPRs did not have properties (elastic modulus, glass transition temperature) to replace the commercial ones in their main applications. Therefore, the further development of UPR formulations with higher biobased content is highly desirable.

In this work, fully biobased UPs were prepared using different combinations of a set of renewable monomers (viz., FuAc, ItaAc, SeAc, AdAc, SuAc, PG, Iso, PDO and 1,4-butanediol (BDO)). The monomers were carefully selected according to their structure envisaging the standard thermomechanical properties expected for a UPR. After the crosslinking with Sty, the properties of the new UPRs were compared with a commercial product that is commonly used in very demanding markets (e.g. synthetic marble and marine industry). In addition, the bulk polymerization method employed for the synthesis of the UPs does not require the use of toxic solvents as other available processes (e.g. azeotropic distillation [14, 15]).

It should be pointed out that, to the best of our knowledge, the synthesis of an UP totally based on renewable monomers has never been reported to afford UPRs (crosslinked with Sty) that have thermal and mechanical properties similar to those of a commercial UPR.

\section{Experimental section}

\subsection{Materials}

FuAc (99\%), SeAc (94.5\%), PG (99\%), Iso (98\%), Sty $(>99 \%)$ and tetrahydrofuran (THF, $>95 \%$ ) were purchased from Sigma-Aldrich (St. Louis, USA). AdAc (>99\%) and PDO (>98\%) were purchased from TCI Europe (Zwijndrecht, Belgium). SuAc (99\%), ItaAc (99\%), BDO (>99\%) and potassium hydroxide solution ( $1 \mathrm{~N}$, in ethanol) were purchased from Acros Organic (Geel, Belgium). Cobalt Octoate $(\mathrm{CoO})$ was purchased from AGAMI (Moreira, Portugal), phenolphthalein was obtained from Riedelde-Häen (Bucharest, Romania), methyl ethyl ketone peroxide (MEKP) from Algarplás (Sta Bárbara de Nexe, Portugal) and hydroquinone (HQ, $>99 \%$ ) was purchased from Analar (Radnor, USA). Deuterated THF (THF- $\mathrm{d}_{8}, 99.5 \%$ ) was purchased from Eurisotop (Saint-Aubin, France). All the reactants were used as received, unless otherwise stated.

\subsection{Synthesis of the UPs}

The biobased UPs were synthesized by uncatalysed bulk polycondensation reaction. The monomers and the radical inhibitor HQ $(0.01 \%$ of the total weight $)$ were charged in a four head reactor equipped with a mechanical stirrer, a nitrogen inlet and a condenser connected to a round-bottom flask. The polycondensation reactions were carried out at $205^{\circ} \mathrm{C}$. The end of the reaction was set when the acid value (AV) reached a constant value (determined according to ASTM 109-01). Table 1 presents the molar amounts

Table 1. Reaction conditions for the synthesized biobased UPs

\begin{tabular}{|c|c|c|c|c|}
\hline Formulations & $\begin{array}{c}\boldsymbol{n}_{\text {saturated acid }} \\
\text { [mol] }\end{array}$ & $\begin{array}{c}\boldsymbol{n}_{\text {unsaturated acid }} \\
\text { [mol] }\end{array}$ & $\begin{array}{c}\boldsymbol{n}_{\text {glycols }} \\
\text { [mol] }\end{array}$ & $\begin{array}{c}t \\
{[\mathbf{h}]}\end{array}$ \\
\hline Resipur $9837^{\circledR}$ & 0.33 & 0.14 & 0.53 & - \\
\hline BioUP_1 & $\begin{array}{c}0.33 \\
(\mathrm{SuAc})\end{array}$ & $\begin{array}{c}0.14 \\
(\mathrm{FuAc})\end{array}$ & $\begin{array}{l}0.53 \\
(\mathrm{PG})\end{array}$ & 12.0 \\
\hline BioUP_2 & $\begin{array}{c}0.33 \\
(\mathrm{AdAc})\end{array}$ & \multirow{2}{*}{$\begin{array}{c}0.14 \\
(\mathrm{FuAc})\end{array}$} & \multirow{2}{*}{$\begin{array}{l}0.53 \\
(\mathrm{PG})\end{array}$} & 12.0 \\
\hline BioUP_3 & $\begin{array}{c}0.33 \\
(\mathrm{SeAc})\end{array}$ & & & 10.5 \\
\hline BioUP_4 & \multirow{3}{*}{$\begin{array}{c}0.33 \\
(\mathrm{SuAc})\end{array}$} & \multirow{3}{*}{$\begin{array}{c}0.14 \\
(\mathrm{FuAc})\end{array}$} & $\begin{array}{c}0.53 \\
(\mathrm{PDO})\end{array}$ & 5.0 \\
\hline BioUP_5 & & & $\begin{array}{c}0.53 \\
(\mathrm{BDO})\end{array}$ & 8.0 \\
\hline BioUP_6 & & & $\begin{array}{l}0.53 \\
\text { (Iso) }\end{array}$ & 7.0 \\
\hline BioUP_7 & $\begin{array}{c}0.33 \\
(\mathrm{SuAc})\end{array}$ & $\begin{array}{c}0.14 \\
(\text { ItaAc) }\end{array}$ & $\begin{array}{l}0.53 \\
(\mathrm{PG})\end{array}$ & 5.0 \\
\hline
\end{tabular}

$n$ : molar amounts of monomers [mol]; $t$ : reactions time $[\mathrm{h}]$ 
of monomers, as well as the reaction times used in the different polycondensations.

\subsection{Preparation of the UPRs}

The biobased UPs (BioUPs) were dissolved in $32 \mathrm{wt} \%$. Sty. The initiator MEKP (2 wt \%.) and accelerator $\mathrm{CoO}(1 \mathrm{wt} \%$.) were added under continuous stirring until a homogeneous mixture was obtained [16]. The formulations were cured in a Teflon mold $(16 \times 7 \times 0.5 \mathrm{~mm})$ at room temperature for 24 hours and post-cured at $80^{\circ} \mathrm{C}$ for 3 hours $[17,18]$.

\subsection{Characterization}

\subsubsection{Chemical structure identification}

ATR-FTIR analysis of UPs was carried out with a Jasco FT-IR-4200 spectrometer, from Jasco Inc. (Easton, USA) equipped with a Golden Gate Single Reflection Diamond ATR. Data collection was performed with $4 \mathrm{~cm}^{-1}$ spectral resolution and 64 accumulations.

${ }^{1} \mathrm{H}$ NMR spectra were recorded on a Bruker Avance III $400 \mathrm{MHz}$ spectrometer, from Bruker (Billerica, USA) using a $5 \mathrm{~mm}$ TIX triple resonance detection probe, in THF- $\mathrm{d}_{8}$, at room temperature. Tetramethylsilane (TMS) was used as the internal reference.

\subsubsection{Molecular weight distribution}

The molecular weight and molecular weight distribution of the BioUPs were determined using high performance size exclusion chromatography HPSEC; Viscotek with a refractive index (RI) detectors. The column set consisted of one Viscotek Tguard column $(8 \mu \mathrm{m})$, one Viscotek T2000 column $(6 \mu \mathrm{m})$, one Viscotek T3000 column $(6 \mu \mathrm{m})$ and one Viscotek LT4000L column $(7 \mu \mathrm{m})$, from Malvern (Malvern, UK). HPLC pump was set with a flow rate of $1 \mathrm{~mL} / \mathrm{min}$. The system was also equipped with an online degasser. The tests were carried out at $30^{\circ} \mathrm{C}$ using an Elder $\mathrm{CH}-150$ heater. The samples were filtered through a polytetrafluoroethylene (PTFE) membrane with $0.2 \mu \mathrm{m}$ pore, before the injection $(100 \mu \mathrm{L})$. THF was used as the eluent. Conventional calibration was done with narrow polystyrene standards $\left(M_{\mathrm{n}}[(\mathrm{g} / \mathrm{mol}]=1980 ; 4290 ; 10050 ; 30300\right.$; 52220 and 96000).

\subsubsection{Thermal properties}

The differential scanning calorimetry (DSC) studies were performed in a TA Instruments Q100 model, equipped with a RCS90 cooling unit, from TA
Instruments (New Castle, USA). The heat flow and the heat capacity were calibrated at $5^{\circ} \mathrm{C} / \mathrm{min}$ using indium and sapphire standards, respectively. The samples were analyzed in aluminum pans with an ordinary aluminum lid loosely placed. A heating rate of $5^{\circ} \mathrm{C} / \mathrm{min}$ and a dry nitrogen purge flow of $50 \mathrm{~mL} / \mathrm{min}$ were used in all measurements. The samples were heated at $5^{\circ} \mathrm{C} / \mathrm{min}$ from -80 to $200^{\circ} \mathrm{C}$, after performing a cycle in which the samples were heated from room temperature to $120^{\circ} \mathrm{C}$ and cooled to $-80^{\circ} \mathrm{C}$ to erase their thermal history.

The viscoelastic properties of the UPs and UPRs were measured by DMTA with a Tritec 2000 DMA, from Triton Technology, Ltd (Keyworth, UK). BioUPs were analyzed in the single cantilever bending geometry using stainless steel material pockets. The properties of BioUPRs were analyzed in the dual cantilever bending geometry. All DMTA measurements were carried out in a -150 to $200^{\circ} \mathrm{C}$ temperature range, at frequencies of 1 and $10 \mathrm{~Hz}$, using a heating rate of $5^{\circ} \mathrm{C} / \mathrm{min}$. The $T_{\mathrm{g}}$ of the UPs and UPRs was determined from the maximum of $\tan \delta$, at $1 \mathrm{~Hz}$.

\subsubsection{Viscosity}

The kinematic viscosity of synthesized UPs was determined by Gardner- Holdt Bubble Viscometer. The sample is placed into a standard viscosity tube and is thermostated at $25^{\circ} \mathrm{C}$. The viscosity of the sample is determined by comparison to the standard bubble viscometer tubes (or Gardner-Holdt tubes) with standard viscosity marked alphabetically, in which an air bubble rises with the same speed as it does in the tube of the sample being tested. The standard tube with the same viscosity as the sample has a letter that can be converted to the kinematic viscosity, in Stokes (St) [19]. The viscosity of all polyesters was determined in a solution of 2:1 by weight of the UP in 2-ethoxyethanol (adapted from [20]).

\subsubsection{Gel content}

The degree of curing of UPRs was determined by the gel content test (according to ASTM D2765). The gel content was determined by Soxhlet extraction using THF as solvent. The samples were weighed and placed in the Soxhlet's extractor for 8 hours. After that, the samples were dried until constant weight, and weighed. Gel content was calculated according to the Equation (1):

Gel content $[\%]=\frac{w_{\mathrm{f}}}{w_{0}} \cdot 100$ 
where $w_{0}$ and $w_{\mathrm{f}}$ represent, respectively, the weight before and after extraction.

\subsubsection{Water contact angles}

The water contact angles (WCA) were measured on the surface of the cured BioUPRs. The analyses were carried out in a Contact Angle System OCA, equipped with Dataphysics SCA20 software. For the measurements, a $10 \mu \mathrm{L}$ drop of distilled water was dispensed, at a rate of $0.5 \mu \mathrm{L} / \mathrm{s}$, and the final WCA was determined as the average of four different drops deposition measurements.

\section{Results and discussion}

\subsection{Polycondensation of UPs based on renewable monomers}

In this work, new biobased UPs were synthesized using bulk polycondensation in the absence of any catalysts. Different biobased glycols and dicarboxylic acids were considered to replace the common petroleum-based feedstocks (Figure 1). The stringent selection of monomers was based not only on their reactivity, but also on the expected properties that they could impart to the UPR (e.g. flexibility, toughness). $\mathrm{SuAc}$, AdAc and SeAc can be considered as potential candidates to replace PhA. The use of different chain lengths allows the design of UPs that, after crosslinking, originate materials with different flexibilities and tensile strength [21]. Concerning glycols, our study intended to evaluate the influence of their structures and level of incorporation in the UPs in the final properties of the UPRs. Typically, the most used diol is PG, which is already commercially available from natural sources [22-25]. The other diols used were PDO, BDO and Iso. The latter, due to its cyclic structure, should contribute to improve the rigidity of the final UPRs. FuAc and ItaAc were studied as biobased sources of doubles bonds, and the influence

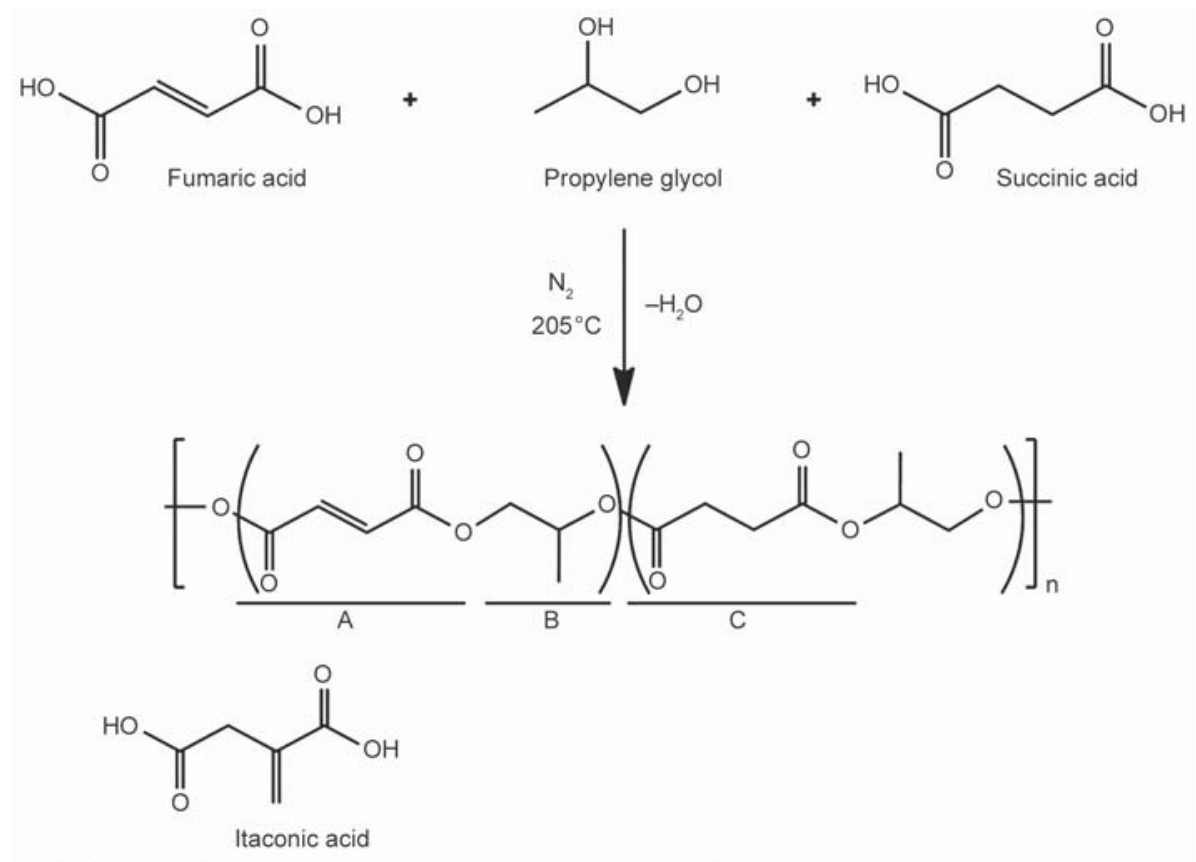

a) Unsaturated acid<smiles>OCCCO</smiles><smiles>OCCCCO</smiles>

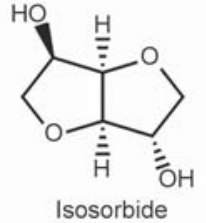

b) Glycols<smiles>O=C(O)CCCCC(=O)O</smiles>

c) Saturated acid<smiles>O=C(O)CCCCCCCCCC(=O)O</smiles>

Figure 1. Synthesis of biobased UPs. The remaining structures $(a, b, c)$ correspond to the different monomers used to prepare the different UPs 
of the position of their double bond in the final properties of UPs and UPRs was evaluated.

The chemical structure of the BioUPs was evaluated by ATR-FTIR and ${ }^{1} \mathrm{H}$ NMR.

All the BioUPs presented similar FTIR spectra, being possible to identify the band corresponding to the stretching vibration of the carbonyl group of the ester linkage [26], at $1722 \mathrm{~cm}^{-1}$, and a band in the region $1280-1240 \mathrm{~cm}^{-1}$, related to the stretching vibration of the $\mathrm{C}-\mathrm{O}-\mathrm{C}$ and $\mathrm{C}-\mathrm{O}$ groups of the ester linkage [27]. A band at $c a .1650 \mathrm{~cm}^{-1}$ was also identified and can be ascribed to the stretching vibration of $\mathrm{C}=\mathrm{C}$ bond in FuAc [28]. Two other bands, at ca. 2980, 2930 and $2860 \mathrm{~cm}^{-1}$, are due to the vibrational modes of the CH stretching [27].

Table 2 summarizes the main bands observed in the BioUPs prepared in this work.

Further insigths onto the chemical structure of biobased UPs were obtained by ${ }^{1} \mathrm{H}$ NMR spectroscopy. Figure 2 presents the ${ }^{1} \mathrm{H}$ NMR spectra of BioUP_1, BioUP_2 and BioUP_3, synthesized with different saturated biobased diacids. The integration area of the peaks is indicated in brackets in all spectra.

In all spectra (Figure 2), it is possible to identify the peaks belonging to the $-\mathrm{CH}_{3}$ protons of $\mathrm{PG}$, at 1.25 $1.30 \mathrm{ppm}$ (d) [4]. The signals of the $-\mathrm{CH}_{2}$ protons belonging to this diol are seen at 3.7-4.3 ppm (b) and the $-\mathrm{CH}$ proton at $5.10 \mathrm{ppm}$ (c). The signals between 6.5 and $7.0 \mathrm{ppm}$ (a) correspond to the protons of the double bonds of FuA moieties [29]. As expected, the presented spectra exhibit distinct peaks for the saturated dicarboxylic acid moieties. In the spectrum of BioUP 1, it is possible to distinguish the protons of the $-\mathrm{CH}_{2}$ due to the SuAc structure at 2.4 $2.8 \mathrm{ppm}$ (e) [4]. The BioUP_2 presents the signals of AdAc at $2.29 \mathrm{ppm}(\mathrm{e})$ and $1.62 \mathrm{ppm}(\mathrm{f})$, corresponding to the $-\mathrm{CH}_{2} \mathrm{CH}_{2} \mathrm{C}=\mathrm{O}$ and $-\mathrm{CH}_{2} \mathrm{CH}_{2} \mathrm{C}=\mathrm{O}$ protons, respectively [4]. Furthermore, the characteristic

Table 2. Main IR bands and respective assignments of the synthesized BioUPs

\begin{tabular}{|l|c|c|c|}
\hline \multirow{2}{*}{ Formulation } & \multicolumn{3}{|c|}{$\begin{array}{c}\text { Infrared Bands } \\
\text { [cm }\end{array}$} \\
\cline { 2 - 4 } & $\mathbf{v}_{\mathbf{C}=\mathbf{0} \text {, ester }}$ & $\mathbf{v}_{\mathbf{C}-\mathbf{O} \text {, ester }}$ & $\mathbf{v}_{\mathbf{C}=\mathbf{C}}$ \\
\hline BioUP_1 & 1722 & 1249 & 1644 \\
\hline BioUP_2 & 1725 & 1250 & 1645 \\
\hline BioUP_3 & 1727 & 1253 & 1642 \\
\hline BioUP_4 & 1729 & 1249 & 1643 \\
\hline BioUP_5 & 1725 & 1255 & 1643 \\
\hline BioUP_6 & 1721 & 1255 & 1644 \\
\hline BioUP_7 & 1726 & 1250 & 1642 \\
\hline
\end{tabular}

peaks of SeAc can be identified in the spectrum of BioUP_3 with the $-\mathrm{CH}_{2} \mathrm{CH}_{2} \mathrm{CH}_{2} \mathrm{C}=\mathrm{O}$ protons at $1.32 \mathrm{ppm}(\mathrm{g}), \quad-\mathrm{CH}_{2} \mathrm{CH}_{2} \mathrm{CH}_{2} \mathrm{C}=\mathrm{O}$ protons at $1.59 \mathrm{ppm}$ (f) and $-\mathrm{CH}_{2} \mathrm{CH}_{2} \mathrm{CH}_{2} \mathrm{C}=\mathrm{O}$ protons at $2.27 \mathrm{ppm}(\mathrm{e})$ [30].

The chemical composition of formulations containing different biobased glycols were also studied by ${ }^{1} \mathrm{H}$ NMR spectroscopy. The corresponding spectra is presented in Figure 3. As expected, both UPs spectra show the characteristic resonances attributed to the $-\mathbf{H C}=\mathrm{CH}-$ of FuAc at $\delta \sim 6.8 \mathrm{ppm}$ (a) and the SuAc units at 2.5-2.7 ppm (e) [31]. For BioUP_4, the proton resonances are in accordance with the anticipated chemical structure, with the $\mathrm{OCH}_{2}$ protons of FuAcPDO and SuAc-PDO at $4.27 \mathrm{ppm}$ (b) and $4.13 \mathrm{ppm}$ (d), respectively, and $\mathrm{OCH}_{2} \mathrm{CH}_{2}$ protons at 2.00$1.93 \mathrm{ppm}$ (c) [13]. The BioUP_5 spectrum shows peaks at $3.5 \mathrm{ppm}$ (b') and $1.53 \mathrm{ppm}$ (a'), corresponding to unreacted BDO. This unexpected result was confirmed by repeating the polymerization two times and showed the low reactivity of this monomer. Also, the ${ }^{1} \mathrm{H}$ NMR spectrum of BioUP_6 revelead the presence of some unreacted Iso. The presence of unreacted Iso in the final product can be ascribed to lower reactivity during the polycondensation, caused by the presence of steric hindered endo-hydroxyl groups in its structure [10,12,31].

Figure 4 presents the ${ }^{1} \mathrm{H}$ NMR spectrum of BioUP_7, with ItaAc. As expected, when compared to the ${ }^{1} \mathrm{H}$ NMR spectrum of BioUP_1, the main difference concerns the resonances corresponding to the protons of ItaAc. The resonances ascribed to the unsaturated diacid can be identified at $6.3 \mathrm{ppm}\left(\mathrm{a}_{1}\right)$, $5.7 \mathrm{ppm}\left(\mathrm{a}_{2}\right)$ and $3.35 \mathrm{ppm}\left(\mathrm{a}_{3}\right)[31,32]$. It should also be pointed out the presence of the protons characteristic of mesaconate moieties at ca. $6.71 \mathrm{ppm}\left({ }^{*}\right)$, resulting from the isomerization of itaconate moieties [31].

The relative molar amount of the incorporated monomers in the UPs structure was evaluated taking into account the integral values of the signals corresponding to the different monomers in the structure. The results are shown in Table 3.

The data presented in Table 3 reveals some differences between the molar amount of the monomers in the feed and their incorporation in the final structure of the UPs. These discrepancies can be due to the loss of more volatile monomers during the synthesis, causing a stoichiometric imbalance, and/or to the different reactivities of the monomers $[4,12]$. 


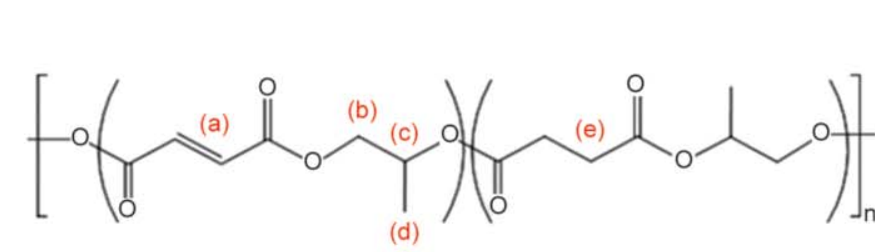

Bio_UP1

(d)

\section{$\mid$}
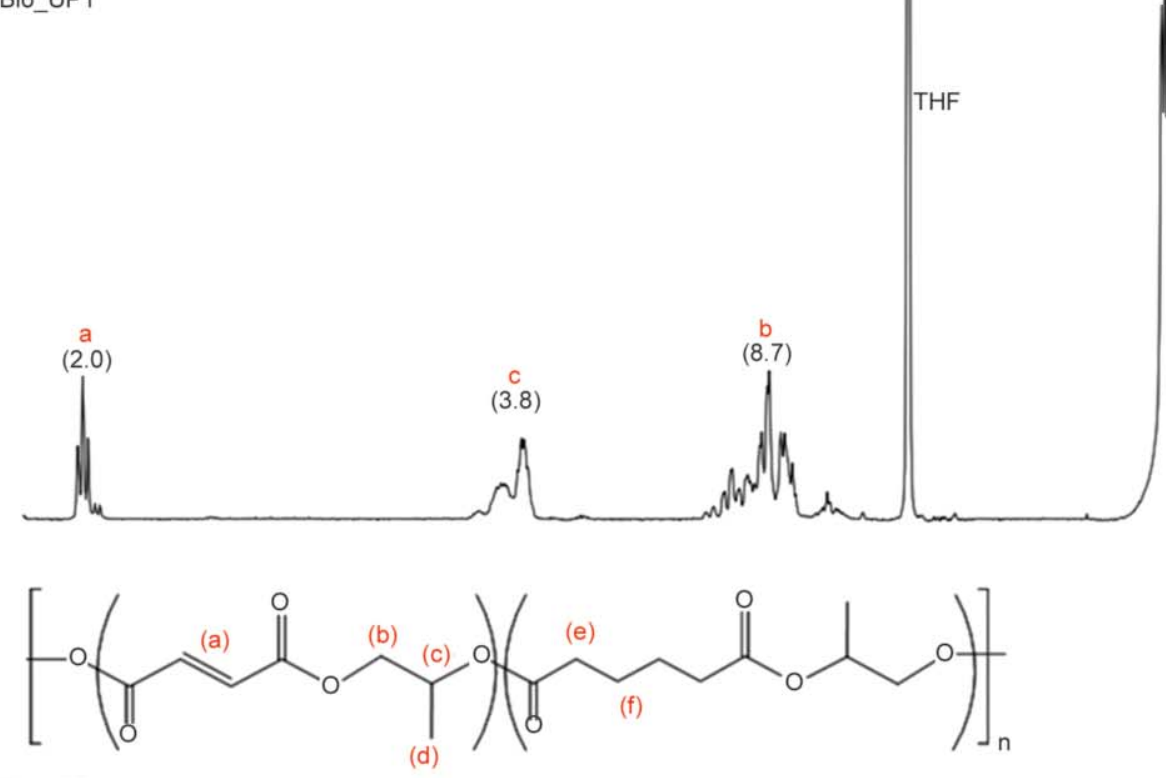

Bio_UP2

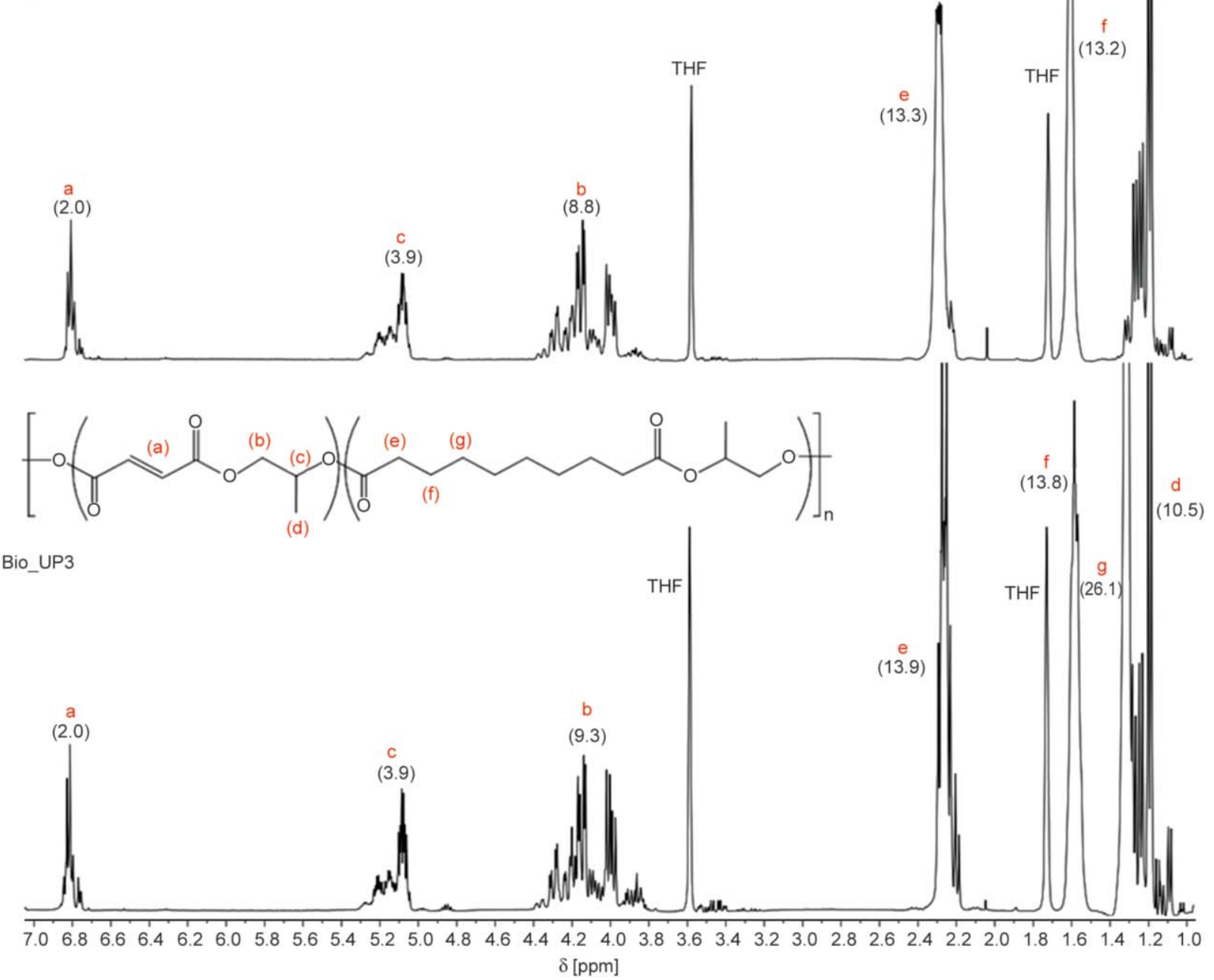

Figure 2. ${ }^{1} \mathrm{H}$ NMR spectra of BioUP_1, BioUP_2 and BioUP_3 


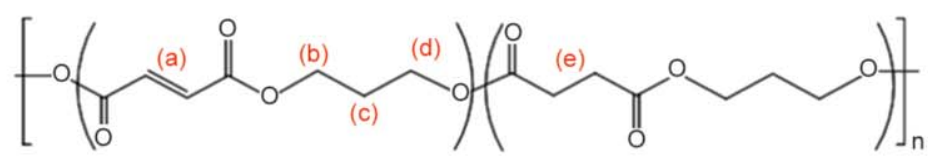

Bio_UP4

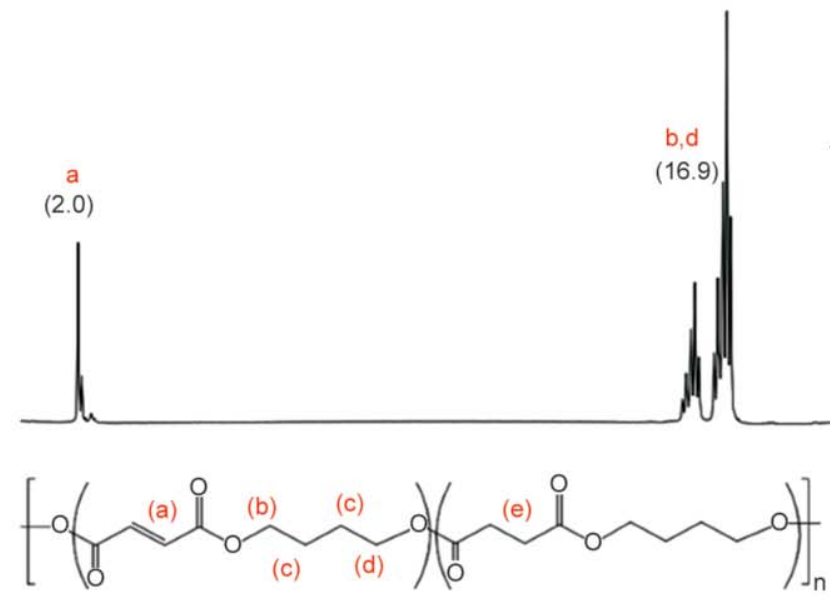

Bio_UP5

$a$
$(2.0)$

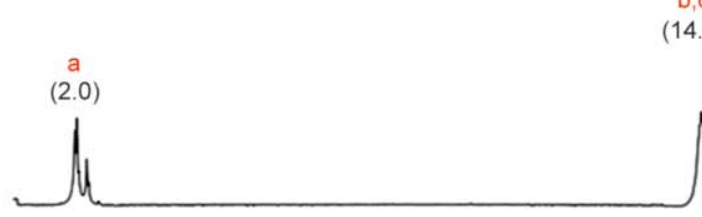

THF

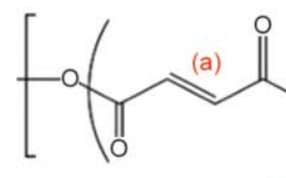

Bio_UP6
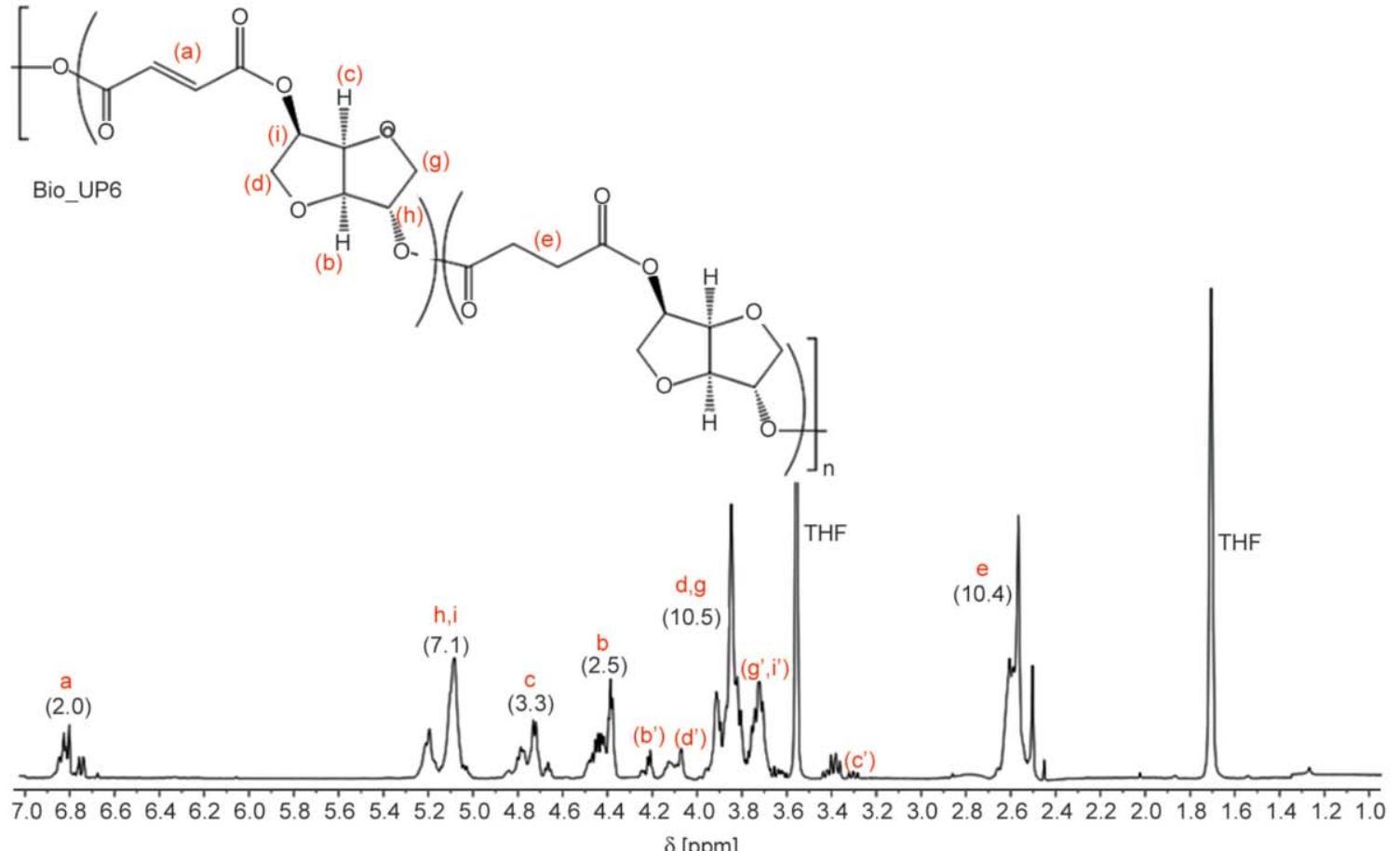

Figure 3. ${ }^{1} \mathrm{H}$ NMR spectra of BioUP_4, BioUP_5 and BioUP_6 


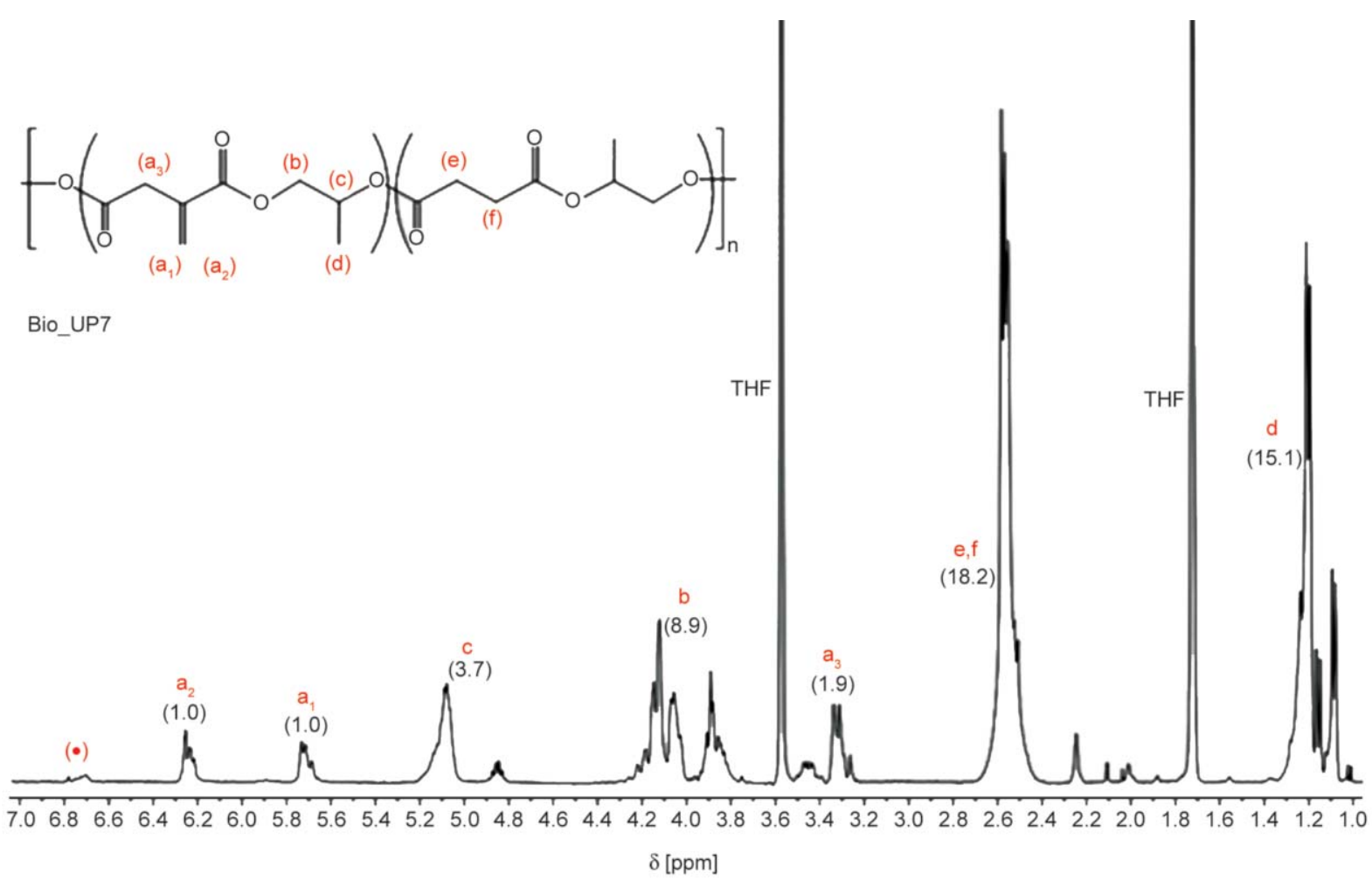

Figure 4. ${ }^{1} \mathrm{H}$ NMR spectrum of BioUP_7. The integration area of the peaks is indicated in brackets in all spectra

Table 3. Comparison between the feed amounts of the different monomers and their relative percentages in the final structure of the UPs, determined by ${ }^{1} \mathrm{H}$ NMR

\begin{tabular}{|l|l|c|c|}
\hline Formulation & Composition & $\begin{array}{c}\text { Initial molar } \\
\text { ratio } \\
{[\%]}\end{array}$ & $\begin{array}{c}\text { Final molar } \\
\text { ratio } \\
\text { [\%] }\end{array}$ \\
\hline BioUP_1 & SuAc/FuAc/PG & $33 / 14 / 53$ & $49 / 11 / 40$ \\
\hline BioUP_2 & $\mathrm{AdAc/FuAc/PG}$ & $33 / 14 / 53$ & $40 / 12 / 48$ \\
\hline BioUP_3 & $\mathrm{SeAc/FuAc/PG}$ & $33 / 14 / 53$ & $41 / 12 / 47$ \\
\hline BioUP_4 & $\mathrm{SuAc/FuAc/PDO}$ & $33 / 14 / 53$ & $38 / 12 / 50$ \\
\hline BioUP_5 & $\mathrm{SuAc/FuAc/BDO}$ & $33 / 14 / 53$ & $41 / 13 / 46$ \\
\hline BioUP_6 & $\mathrm{SuAc/FuAc/Iso}$ & $33 / 14 / 53$ & $38 / 14 / 48$ \\
\hline BioUP_7 & $\mathrm{SuAc/ItaAc/PG}$ & $33 / 14 / 53$ & $49 / 11 / 40$ \\
\hline
\end{tabular}

Regarding the saturated acids, it is possible to observe that SuAc was more incorporated than SeAc and AdAc, whereas these last monomers present similar incorporation. The presented results also suggest that, in general, PG is relatively less incorporated than PDO, probably due to its lower boiling point $\left(188^{\circ} \mathrm{C}\right)$ when compared to the boiling point of PDO $\left(215^{\circ} \mathrm{C}\right)$. On the other hand, the PG can also suffer from some steric hindrance, which might render its incorporation in the UP difficult.

In addition, Iso and BDO presented intermediate incorporation values. Indeed, despite its higher boiling point $\left(235^{\circ} \mathrm{C}\right)$, BDO presented lower incorporation than PDO namely due to the high amount of unreacted monomer at the end of the reaction. It is also interesting to note that the incorporation of FuAc and ItaAc is very similar (BioUP_1 vs BioUP_7), suggesting that the position of $\mathrm{C}=\mathrm{C}$ in the $\mathrm{UM}$ does not affect their incorporation in the UP structure.

Different combinations of biobased monomers (Table 1) were used in the preparation of the UPs and the end of reaction was set when the AV reached a constant value. Typically, the UPs used in the preparation of commercial UPRs have $\mathrm{AV}$ ranging from 25 to $50 \mathrm{mg} \mathrm{KOH} / \mathrm{g}$ [33] and this was the range that was found for the BioUPs prepared in this work. Table 4 summarizes the values of $\mathrm{AV}$, molecular weight $\left(M_{\mathrm{n}}\right)$, the polydispersity $(\nexists)$ as well as the Gardner viscosity values of the BioUPs.

According to Table 4, the BioUPs are characterized by molecular weights ranging from 2700 to $4400 \mathrm{~g} / \mathrm{mol}$, and $D$ between 1.4 and 2.5. These results are in the range of values reported in the literature for UPs [34-37]. Besides molecular weight, the viscosity of the UPs is also a very important characteristic related to commercial applications; UPs with lower viscosity allow the use of a lesser amount of reactive solvent (e.g., Sty). Also, this fact contributes to better cure performances, since higher mobility of the polymeric chains is achieved [38]. As expected, the value of viscosity of the different formulations can be easily tuned by varying the monomers in the 
Table 4. Molecular weight, polydispersity and viscosities of the synthesized BioUPs

\begin{tabular}{|c|c|c|c|c|c|}
\hline Formulation & $\begin{array}{c}\mathrm{AV} \\
{[\mathrm{mg} \mathrm{KOH} / \mathrm{g}]}\end{array}$ & $\begin{array}{c}M_{\mathrm{n}} \\
{[\mathrm{g} / \mathrm{mol}]}\end{array}$ & $\boldsymbol{\theta}$ & $\begin{array}{c}\text { Gardner viscosity } \\
{[\mathrm{St}]}\end{array}$ & $\begin{array}{l}\text { Viscosity } \\
{[\mathrm{Pa} \cdot \mathbf{s}]^{* * * *}}\end{array}$ \\
\hline BioUP_1 & 31 & 4062 & 1.85 & $4.85(\mathrm{RS})$ & 0.51 \\
\hline BioUP_2 & 32 & 4401 & 2.50 & $4.00(\mathrm{P})$ & 0.41 \\
\hline BioUP_3 & 32 & 4170 & 2.38 & $2.31(\mathrm{I}+\mathrm{J})$ & 0.23 \\
\hline BioUP_4 & 29 & 2708 & 1.40 & ** & $* *$ \\
\hline BioUP_5 & $25^{*}$ & \multicolumn{2}{|c|}{ n.d. ${ }^{1)}$} & $* *$ & $* *$ \\
\hline BioUP_6 & $31^{*}$ & $<1980$ & n.d. ${ }^{2)}$ & 7.56 (UV) & 0.88 \\
\hline BioUP_7 & 32 & 3999 & 1.82 & $1.91\left(\mathrm{GH}^{+}\right)$ & 0.20 \\
\hline
\end{tabular}

n.d.: not determined; ${ }^{1}$ n.d. due to insolubility in the eluent for the SEC analysis; ${ }^{2}$ n.d. because the chromatogram falls outside the calibration curve.

${ }^{*}$ UP dissolved only under heating

** solid mixture

${ }^{* * *}$ The viscosity from $\mathrm{St}$ to $\mathrm{Pa} \cdot \mathrm{s}$ was obtained by the following relationship: $\nu[\mathrm{Pa} \cdot \mathrm{s}]=\mu[\mathrm{St}] / \rho$ (the density, $\rho$, was determined by the method of pycnometer)

UPs. Comparing the polyesters with saturated acids, BioUP_1, with SuAc, provides the polyester with higher viscosity, whereas the lowest value was observed for BioUP_3, with SeAc. This result can be explained by the high mobility of the polymeric chains provided by the diacid with longer aliphatic chains $[4,5]$. For these formulations, similar molecular weights were achieved and, consequently, $M_{\mathrm{n}}$ does not have a significant effect on the viscosity of UPs. Regarding the UPs with different glycols, it was not possible to determine the molecular weight for the UP containing Iso (BioUP_6) due to its low value. The low $M_{\mathrm{n}}$ for this sample can result from two factors: 1) The endo isomer of isosorbide is known to suffer steric hindrance, contributing to a lower reactivity; 2) The endo hydroxyl groups have the capacity to establish strong hydrogen bonds during the polycondensation which is translated in an imbalance between the $-\mathrm{OH} /-\mathrm{COOH}$ ratios $[10,39]$. It is interesting to note that, despite its low $M_{\mathrm{n}}$, BioUP_6 is the polyester with the highest viscosity. In the case of Iso, it is reported that the oxolane ring has the ability of establishing inter-chain hydrogen bonds, causing additional chain interactions [5] and, consequently, higher viscosities are expected. For the formulations with PDO and BDO (BioUP_4 and BioUP_5, respectively) it was not possible to determine the Gardner viscosity since UPs were immiscible with 2ethoxyethanol used in the test. The results presented in Table 4 also revealed that BioUP_3 and BioUP_7 have viscosities very close to the commercial polyester (2.38 St (0.27 Pa.s)).

The thermal transitions were evaluated by DSC and DMTA. Figure 5 presents the heat flow curves (from the second heating cycle) of the different UPs.
The different BioUPs, with the exception of BioUP_5, present only one thermal transition corresponding to the $T_{\mathrm{g}}$, indicating that they have an amorphous character. In the BioUP_5 curve, it is clearly seen an endothermic peak corresponding to the melting $\left(107^{\circ} \mathrm{C}\right)$, with an associated enthalpy of $82 \mathrm{~J} / \mathrm{g}$. In this specific case no $T_{\mathrm{g}}$ is detected. This result suggests the predominance of the crystalline domains over their amorphous counterparts, impairing the free movements of the latter, which translates to the absence of a $T_{\mathrm{g}}$. A similar result was obtained for a UP prepared from FuAc and BDO by Farmer and co-workers [31]. The $T_{\mathrm{g}}$ of the BioUPs was also determined by DMTA. Table 5 presents the values of $T_{\mathrm{g}}$ obtained with both techniques.

Regarding the results summarized in Table 5, some differences can be observed in the $T_{\mathrm{g}}$ values of the polyesters, which can be explained by their composition. Comparing BioUP_1, BioUP_2 and BioUP_3, it is possible to see that, when the chain length of

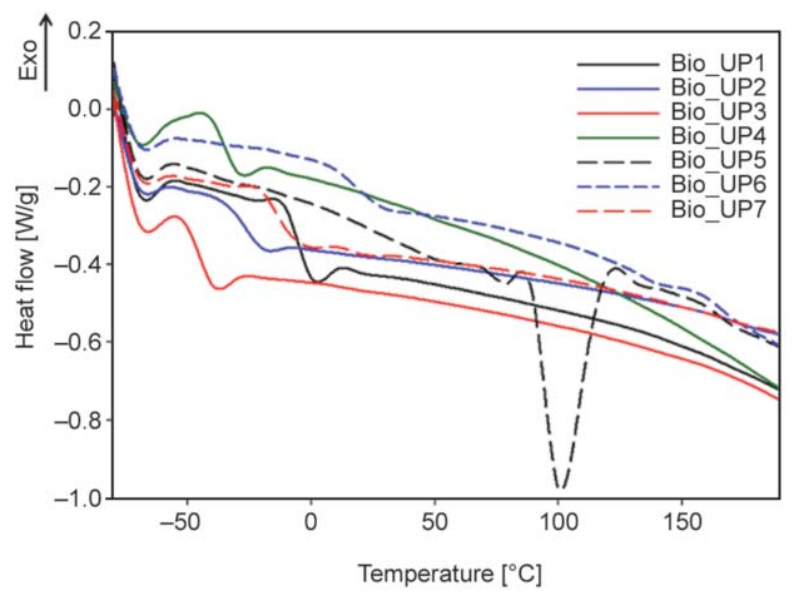

Figure 5. Heat flow curves (from the second heating cycle) of the BioUPs 
Table 5. $T_{\mathrm{g}}$ of the biobased UPs obtained from DMTA and DSC

\begin{tabular}{|l|r|r|}
\hline \multirow{2}{*}{ Formulation } & \multicolumn{2}{|c|}{$\begin{array}{c}\boldsymbol{T}_{\mathbf{g}} \\
{\left[{ }^{\circ} \mathbf{C}\right]}\end{array}$} \\
\cline { 2 - 3 } & DMTA & DSC \\
\hline Commercial UP & 34.0 & 10.4 \\
\hline BioUP_1 & 22.3 & -2.87 \\
\hline BioUP_2 & -2.9 & -26.7 \\
\hline BioUP_3 & -29.4 & -43.2 \\
\hline BioUP_4 & -23.2 & -38.4 \\
\hline BioUP_5 & ${ }^{*}$ & n.d. \\
\hline BioUP_6 & 34.9 & 18.5 \\
\hline BioUP_7 & 4.4 & -12.8 \\
\hline
\end{tabular}

*Broad peak in the $T_{\mathrm{g}}$ region

saturated acids is increased, a decrease of the $T_{\mathrm{g}}$ is observed. According to the literature this fact could be due to the presence of saturated acid with longer chains, which translates to higher chain mobility [4]. Concerning the influence of the glycols, it is also possible to observe that the substitution of PG by PDO leads to lower $T_{\mathrm{g}}$ values. This result can be ascribed to the presence of the methyl pendant group in PG that induces some movement restriction of the polymer chain [31]. On the other hand, BioUP_6 is the formulation with the highest $T_{\mathrm{g}}$ value. This fact can be explained by the cyclic structure of Iso providing additional stiffness to the polymer backbone. For BioUP_5, the DMTA revealed the presence of a very broad peak in the $T_{\mathrm{g}}$ region, which can be explained by a high level of heterogeneity in its composition. Regarding the effect of the UM, it can be seen that Bio_UP7 (with ItaAc) has lower $T_{\mathrm{g}}$ value than BioUP_1 (with FuAc). The UP with ItaAc has pendant double bonds, that can contribute to increase the free volume between the polymeric chains with a concomitant decrease in the $T_{\mathrm{g}}$ value [37]. In spite of the differences between the $T_{\mathrm{g}}$ values determined by the two techniques (DSC and TGA) [40], the $T_{\mathrm{g}}$ values follow the same trend in both.

\subsection{Development and characterization of BioUPRs}

UPRs have a wide-range of industrial applications and the replacement of the fossil based UPs by their biobased counterparts could enlarge the potential markets for these materials. In order to obtain the UPRs, the synthesized UPs were dissolved in Sty, the most widely used reactive solvent for industrial applications, and the mixture was thermally cured in the presence of an initiator and an accelerator $[5,41]$.
Table 6. Gel content and water contact angles (CA) on the resins

\begin{tabular}{|l|c|c|}
\hline & $\begin{array}{c}\text { Gel content } \\
{[\%]}\end{array}$ & $\begin{array}{c}\text { CA } \\
{\left[{ }^{\circ}\right]}\end{array}$ \\
\hline Resipur 9837 ${ }^{\circledR}$ & 99.9 & $82.6 \pm 2.9$ \\
\hline BioUPR_1 & 97.9 & $107.7 \pm 0.1$ \\
\hline BioUPR_2 & 98.1 & $92.9 \pm 0.5$ \\
\hline BioUPR_3 & 98.9 & $93.7 \pm 0.4$ \\
\hline BioUPR_4 & 99.6 & $71.1 \pm 1.3$ \\
\hline BioUPR_7 & 99.2 & $87.9 \pm 1.1$ \\
\hline
\end{tabular}

BioUP_5 and BioUP_6 were not soluble in Sty, and because of that, no UPRs were obtained from these UPs. As already indicated, the polyester with BDO presents high crystallinity (see Figure 5), which could limit its solubility in Sty [31]. The low solubility of Iso based UP can be ascribed to the high polarity of this particular monomer, as described by Sadler and co-workers [9].

Table 6 presents the gel content and the water contact angles for the commercial resin and the obtained BioUPRs

The results suggest that the BioUPRs have high gel content values, which are very similar to the value obtained for the Resipur $9837^{\circledR}$. The results indicate that the composition of the UPRs can be changed without jeopardizing the extent of the crosslinking reactions. The water contact angle (WCA) is also a very important characteristic related to commercial application of UPRs, in particular when used in synthetic marble and components of boats. According to the results presented in Table 6, only the resins BioUPR_1, BioUPR_2 and BioUPR_3 present clearly hydrophobic surfaces, with WCA higher than $90^{\circ}$. BioUPR_7 is the one that present a value closer to the commercial resin. The obtained results suggest that all the UPRs proposed in this work meet the industrial requirements regarding the degree of crosslinking and the contact angle, being this conclusion more evident for the formulation BioUPR_7.

The thermomechanical properties of the commercial and BioUPRs were studied by DMTA, at two frequencies $(1,10 \mathrm{~Hz})$, in a temperature range of -150 to $200^{\circ} \mathrm{C}$. The tests were carried out in multifrequency mode since it allows to distinguish between the frequency dependent processes (e.g., $\alpha$ transition, $T_{\mathrm{g}}$, and secondary transitions, $\gamma$ and $\beta$ ) and those that are non-frequency dependent (e.g., melting, crystallization). The $T_{\mathrm{g}}$ of the UPRs was determined from the maximum of the $\tan \delta$ curve, at $1 \mathrm{~Hz}$. The $T_{\mathrm{g}}$ of the 
materials is important to be determined since it is directly related with their mechanical properties and with their service temperature. Typically, the toughness of a material attains its maximum at a temperature slightly below or at the polymer's $T_{\mathrm{g}}$, temperature at which the polymer chains increase their molecular motion, allowing the material to sustain larger strains without compromising the strength [42]. The DMTA traces of the UPRs, at $1 \mathrm{~Hz}$, are presented in Figure 6.

According to the results presented in Figure 6 it is possible to observe that the changes in the monomers used had a significant impact on the thermomechanical properties. Figure 6a shows the $E^{\prime}$ trace of the studied resins. In the glass region, with lower $E^{\prime}$ value, the commercial resin is less rigid than the BioUPRs. This trend is also observed for high temperatures, in the rubbery plateau. As expected, in the glass transition region, a sharp decrease in the $E^{\prime}$ is observed for the UPRs under study, being more pronounced for the commercial resin. In this resin, the segmental motions starts nearly at the same temperature and, as a consequence, the temperature range at which the $E^{\prime}$ decreases is narrower. It should be mentioned that,

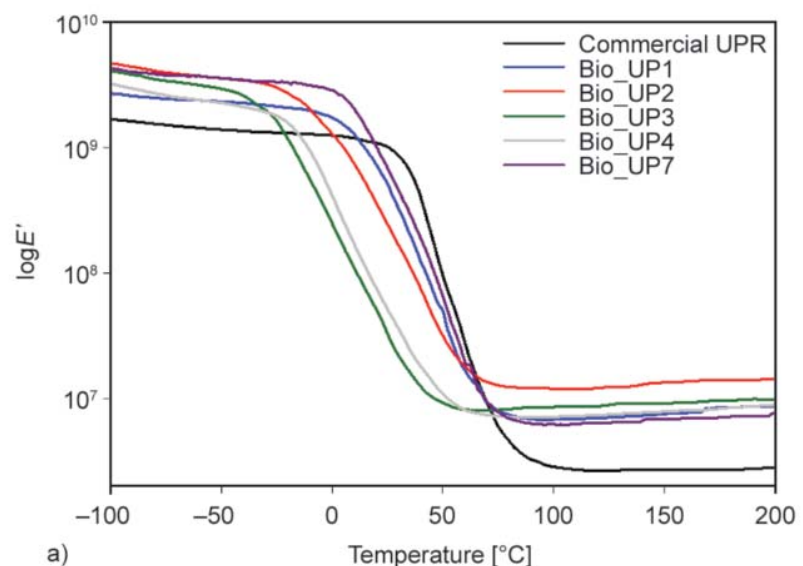

in the temperature range of $0-80^{\circ} \mathrm{C}$, BioUPR 1 , BioUPR_2 and BioUPR_7 are very close to the commercial resin. This fact is very important since this is the normal working range temperature for these materials in industrial applications (namely for coatings and reinforcement materials). The $E^{\prime \prime}$ profile (Figure $6 \mathrm{~b}$ ) presents two different peaks for the all resins under study that can be ascribed to a secondary transition, at lower temperatures, and to the main transition. The latter occurs at different temperatures for the different materials, indicating that the composition of the BioUPRs influences their ability to dissipate energy. Moreover, in the same temperature ranges, two peaks in $\tan \delta$ curve are expected. Figure $6 \mathrm{c}$ presents the $\tan \delta$ traces for all resins under study. At high temperatures, it is possible to identify the $\alpha$ transition, corresponding to the $T_{\mathrm{g}}$. The UPRs present different $T_{\mathrm{g}}$ values, and a shoulder can also be observed in all biobased resins ( $T_{\text {shoulder }}$, in Table 7). This fact might be ascribed to the presence of two different phases that start to move at different temperatures $[2,13]$. At negative temperatures, it is also possible to identify a peak that is presented in the same region for all resins and does not seem to be dependent on

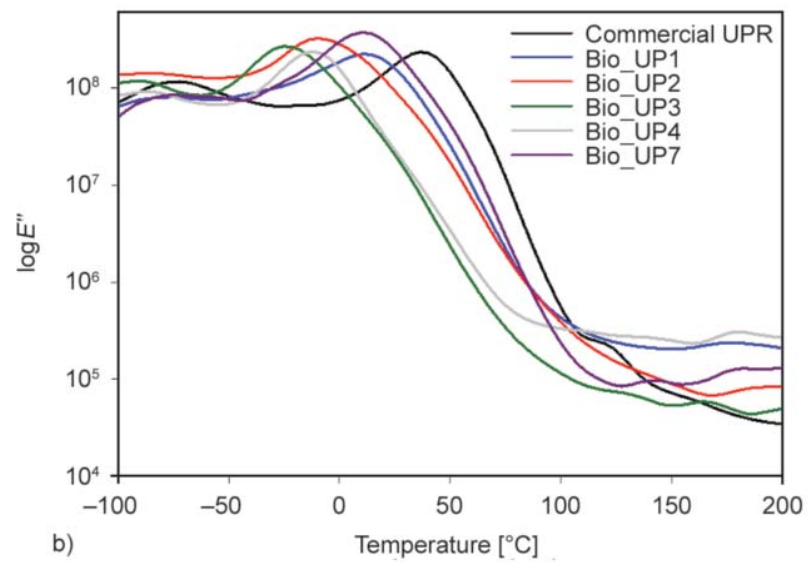

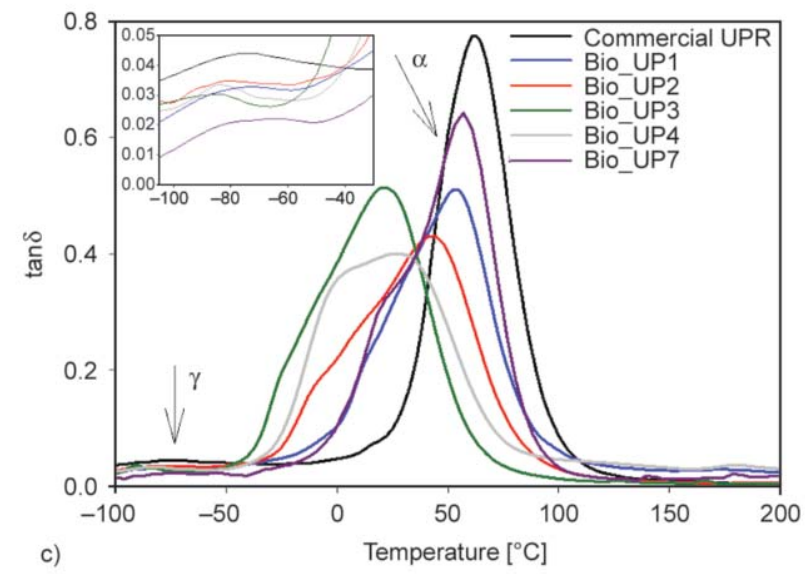

Figure 6. DMTA traces of the commercial and biobased UPRs in terms of $E^{\prime}$ (a), $E^{\prime \prime}$ (b) and $\tan \delta$ (c) 
the UPs composition. In literature, it is described that this transition (denoted as $\gamma$ transition) can be explained by the motions of the aromatic group in poly(styrene) or oligo(styrene) moieties [2, 43]. On the other hand, it is also possible to observe that the $\tan \delta \operatorname{traces}$ are relatively broad. This feature could be interesting for same applications that require similar properties in a wide range of temperatures. It is also worth to note that $\tan \delta$ peaks have different amplitudes, which indicates that the UPRs have different capacities to dissipate energy. According to the tan $\delta$ traces, the Resipur $9837^{\circledR}$ is the resin with the highest capacity to dissipate energy, followed by BioUPR_7. This result can be particularly relevant since the capacity to dissipate energy has a decisive impact on different mechanical properties (e.g. impact strength).

In Table 7 are summarized the main values obtained from DMTA data.

Looking at the values presented in Table 7, some conclusions can be drawn regarding the influence of composition in the elastic and viscous properties of the materials, at $25^{\circ} \mathrm{C}$. Concerning the influence of the diacids, it is clear that the biobased UPRs made from UPs with diacids with shorter chain lengths are more rigid ( $\left.E_{\text {BioUPR_1 }}^{\prime}>E_{\text {BioUPR_2 }}^{\prime}>E_{\text {BioUPR_3 }}^{\prime}\right)$. BioUPR_1 also presents the highest $E^{\prime \prime}$ value of these three formulations, corresponding to a higher capacity of the material to dissipate energy as heat due to viscous molecular motions. These results indicate that the use of diacids with shorter chain length leads to a more cohesive crosslinked network, which translates to a higher rigidity (higher $E^{\prime}$ ) and also to a higher amount of energy that is released when the chains start to move (higher $E^{\prime \prime}$ ). One can also see that the replacement of PG by PDO (BioUPR_1 vs BioUPR_4) led to a significant decrease in the $E^{\prime}$ values. This result was somewhat unexpected. PG has a pendant methyl group in its structure which increases the free volume between the polymeric chains and, consequently, provides a less compact polymeric matrix [44]. Thus, it should be expected resins with lower $E^{\prime}$ values. Nevertheless, for the resins under study, it seems that the pendant group of this glycol restrains the movements of the chains and higher $E^{\prime}$ values are observed. Accordingly, Bio_UPR1 has a lower value of $E^{\prime \prime}$. It should be mentioned that BioUPR_7 is the biobased UPR that presents the $E^{\prime}$ and $E^{\prime \prime}$ values closer to the commercial UPR. Moreover, it should be also mentioned that Bio_UPR7 was a $T_{\mathrm{g}}$ value very close to the Resipur $9837^{\circledR}$, which suggests that this Bio_UPR is a reliable candidate to replace the commercial resin in its common applications.

\section{Conclusions}

In this work, different UPs were prepared with monomers currently obtained from renewable resources in order to produce BioUPRs with different characteristics, as similar as possible to those of a commercial resin, Resipur $9837^{\circledR}$.

The BioUPs were successfully synthesized with biobased monomers by bulk polycondensation, in the absence of toxic solvents and catalysts. The UPs' structures were confirmed by FTIR and ${ }^{1} \mathrm{H}$ NMR spectroscopies. The thermal properties were also evaluated and revealed that the $T_{\mathrm{g}}$ of the BioUPs showed to be dependent on the composition, with the higher values observed for BioUP_1 and BioUP_6 (22.3 and $24.9^{\circ} \mathrm{C}$, respectively).

Regarding the BioUPRs, prepared using Sty as reactive solvent, high gel content values were obtained and their hydrophobicity is very similar to that of the commercial resin.

DMTA analysis presented two transitions ( $\gamma$ and $\alpha$ ) for all resins. Although the BioUPRs have presented interesting thermomechanical characteristics, BioUPR_ 7 is the resins that present closer properties to the commercial UPR.

Table 7. Thermomechanical parameters of the studied UPRs

\begin{tabular}{|l|c|c|c|c|c|c|}
\hline \multicolumn{1}{|c|}{ Formulation } & $\begin{array}{c}\boldsymbol{E}^{\prime}{ }_{\mathbf{2 5}}{ }^{\circ} \mathbf{C} \\
{[\mathbf{M P a}]}\end{array}$ & $\begin{array}{c}\boldsymbol{E}^{{ }^{\prime} \mathbf{2 5}^{\circ} \mathbf{C}} \\
{[\mathbf{M P a}]}\end{array}$ & $\begin{array}{c}\boldsymbol{T}_{\boldsymbol{\gamma}} \\
{\left[{ }^{\circ} \mathbf{C}\right]}\end{array}$ & $\begin{array}{c}\boldsymbol{T}_{\text {shoulder }} \\
{\left[{ }^{\circ} \mathbf{C}\right]}\end{array}$ & $\begin{array}{c}\boldsymbol{T}_{\mathbf{g}} \\
{\left[{ }^{\circ} \mathbf{C}\right]}\end{array}$ & $\tan \boldsymbol{\delta}_{\max }$ \\
\hline Resipur 9837 ${ }^{\circledR}$ & $100 \cdot 10^{1}$ & 102.0 & -75.4 & - & 62.9 & 0.77 \\
\hline BioUPR_1 & 523.0 & 163.0 & -76.3 & 13.3 & 53.4 & 0.52 \\
\hline BioUPR_2 & 240.0 & 83.3 & -82.5 & -10.7 & 45.6 & 0.45 \\
\hline BioUPR_3 & 32.7 & 16.3 & -84.3 & -24.6 & 21.8 & 0.52 \\
\hline BioUPR_4 & 51.8 & 21.0 & -84.1 & -1.0 & 27.1 & 0.40 \\
\hline BioUPR_7 & 657.0 & 232.0 & -74.5 & 19.2 & 58.0 & 0.67 \\
\hline
\end{tabular}




\section{Acknowledgements}

This work was developed during the Green UP project in collaboration with Resiquímica- Resinas Químicas, S.A. The authors gratefully acknowledge the project PT 2020 SI I\&DT, Lisboa-01-0247-FEDER-010955 for financial support. NMR data was obtained at the Nuclear Magnetic Resonance Laboratory of the Coimbra Chemistry Centre, facility which is supported in part by FEDER - European Regional Development Fund through the COMPETE Programme (Operational Programme for Competitiveness) and by National Funds through FCT - Fundação para a Ciência e a Tecnologia (Portuguese Foundation for Science and Technology) through grants REEQ/481/QUI/2006, RECI/QEQ-QFI/0168/ 2012, CENTRO-07-CT62-FEDER-002012, and Rede Nacional de Ressonância Magnética Nuclear (RNRMN). Ana C. Fonseca acknowledges FCT: SFRH/BPD/99982/2014.

\section{References}

[1] Mustapha S., Rahmat A., Arsad A., Yeong S.: Novel bio-based resins from blends of functionalised palm oil and unsaturated polyester resin. Materials Research Innovations, 18, S6_326-S6_330 (2014). https://doi.org/10.1179/1432891714Z.000000000978

[2] Sanchez E. M. S., Zavaglia C. A. C., Felisberti M. I.: Unsaturated polyester resins: Influence of the styrene concentration on the miscibility and mechanical properties. Polymer, 41, 765-769 (2000). https://doi.org/10.1016/S0032-3861(99)00184-6

[3] Rusmirović J. D., Trifković K. T., Bugarski B., Pavlović V. B., Dzunuzović J., Tomić M., Marinković A. D.: High performance unsaturated polyester based nanocomposites: Effect of vinyl modified nanosilica on mechanical properties. Express Polymer Letters, 10, 139-159 (2016). https://doi.org/10.3144/expresspolymlett.2016.14

[4] Gonçalves F. A., Costa C. S., Fabela I. G., Farinha D., Faneca H., Simões P. N., Serra A. C., Bártolo P. J., Coelho J. F.: 3D printing of new biobased unsaturated polyesters by microstereo-thermalithography. Biofabrication, 6, 1-14 (2014).

https://doi.org/10.1088/1758-5082/6/3/035024

[5] Sadler J. M., Toulan F. R., Palmese G. R., La Scala J. J.: Unsaturated polyester resins for thermoset applications using renewable isosorbide as a component for property improvement. Journal of Applied Polymer Science, 132, 1-11 (2015).

https://doi.org/10.1002/app.42315

[6] Harmsen P. F. H., Hackmann M. M., Bos H. L.: Green building blocks for bio-based plastics. Biofuels, Bioproducts and Biorefining, 8, 306-324 (2014). https://doi.org/10.1002/bbb.1468

[7] Isikgor F. H., Becer C. R.: Lignocellulosic biomass: A sustainable platform for the production of bio-based chemicals and polymers. Polymer Chemistry, 6, 4497 4559 (2015).

https://doi.org/10.1039/C5PY00263J
[8] Robert T., Friebel S.: Itaconic acid - A versatile building block for renewable polyesters with enhanced functionality. Green Chemistry, 18, 2922-2934 (2016). https://doi.org/10.1039/C6GC00605A

[9] Sadler J. M., Toulan F. R., Nguyen A-P., Kayea R. V., Ziaee S., Palmese G. R., La Scala J. J.: Isosorbide as the structural component of bio-based unsaturated polyesters for use as thermosetting resins. Carbohydrate Polymers, 100, 97-106 (2014).

https://doi.org/10.1016/j.carbpol.2013.04.036

[10] Jasinska L., Koning C. E.: Unsaturated, biobased polyesters and their cross-linking via radical copolymerization. Journal of Polymer Science Part A: Polymer Chemistry, 48, 2885-2895 (2010).

https://doi.org/10.1002/pola.24067

[11] Goerz O., Ritter H.: Polymers with shape memory effect from renewable resources: Crosslinking of polyesters based on isosorbide, itaconic acid and succinic acid. Polymer International, 62, 709-712 (2013).

https://doi.org/10.1002/pi.4443

[12] Fonseca A. C., Lopes I. M., Coelho J. F. J., Serra A. C.: Synthesis of unsaturated polyesters based on renewable monomers: Structure/properties relationship and crosslinking with 2-hydroxyethyl methacrylate. Reactive and Functional Polymers, 97, 1-11 (2015).

https://doi.org/10.1016/j.reactfunctpolym.2015.10.002

[13] Sousa A. F., Fonseca A. C., Serra A. C., Freire C. S. R., Silvestre A. J. D., Coelho J. F. J.: New unsaturated copolyesters based on 2,5-furandicarboxylic acid and their crosslinked derivatives. Polymer Chemistry, 7, 1049-1058 (2016).

https://doi.org/10.1039/C5PY01702E

[14] Belgacem M. N., Gandini A.: Monomers, polymers and composites from renewable resources. Elsevier, Amsterdam (2008).

[15] Malik M., Choudhary V., Varma I. K.: Current status of unsaturated polyester resins. Journal of Macromolecular Science Part C: Polymer Reviews, 40, 139-165 (2000). https://doi.org/10.1081/MC-100100582

[16] Martín J. L.: Kinetic analysis of an asymmetrical DSC peak in the curing of an unsaturated polyester resin catalysed with MEKP and cobalt octoate. Polymer, 40, 3451-3462 (1999). https://doi.org/10.1016/S0032-3861(98)00556-4

[17] Lai C-M., Rozman H. D., Tay G-S.: Palm oil-based unsaturated polyester: Activation energy and swelling properties. Polymer Engineering and Science, 53, 11381145 (2013). https://doi.org/10.1002/pen.23367

[18] Atta A. M., Elsaeed A. M., Farag R. K., El-Saeed S. M.: Synthesis of unsaturated polyester resins based on rosin acrylic acid adduct for coating applications. Reactive and Functional Polymers, 67, 549-563 (2007). https://doi.org/10.1016/j.reactfunctpolym.2007.03.009 
[19] Jacobs W.: Amino resins (reaction products of melamine, urea, etc., with formaldehyde and alcohols). in 'Paint and coating testing manual: $15^{\text {th }}$ edition of the GardnerSward handbook' (eds.: Koleske J. V.) ASTM International, West Conshohocken, 72-80 (2012).

[20] Paparatto P., Vargiu S., Parodi A., Passalenti B.: Moulding compositions including an unsaturated polyester. U.S. Patent 4077939, USA (1978).

[21] Irfan M. H.: Chemistry and technology of thermosetting polymers in construction applications. Springer, Dordrecht (1998).

[22] Saxena R. K., Anand P., Saran S., Isar A., Agarwal L.: Microbial production and applications of 1,2-propanediol. Indian Journal of Microbiology, 50, 2-11 (2010). https://doi.org/10.1007/s12088-010-0017-x

[23] Marinas A., Bruijnincx P., Ftouni J., Urbano F. J., Pinel C.: Sustainability metrics for a fossil- and renewablebased route for 1,2-propanediol production: A comparison. Catalysis Today, 239, 31-37 (2015). https://doi.org/10.1016/j.cattod.2014.02.048

[24] Siebert D., Wendisch V. F.: Metabolic pathway engineering for production of 1,2-propanediol and 1-propanol by Corynebacterium glutamicum. Biotechnology for Biofuels, 8, 91/1-91/13 (2015).

https://doi.org/10.1186/s13068-015-0269-0

[25] Saxena S.: Applied microbiology. Springer, New Dehli (2015).

[26] Coates J.: Interpretation of infrared spectra, a practical approach. Wiley, Chichester (2000).

[27] Ferreira G. R., Braquehais J. R., da Silva W. N., Machado F.: Synthesis of soybean oil-based polymer lattices via emulsion polymerization process. Industrial Crops and Products, 65, 14-20 (2015).

https://doi.org/10.1016/j.indcrop.2014.11.042

[28] Liu C., Li J., Lei W., Zhou Y.: Development of biobased unsaturated polyester resin containing highly functionalized castor oil. Industrial Crops and Products, 52, 329-337 (2014).

https://doi.org/10.1016/j.indcrop.2013.11.010

[29] Takenouchi S., Takasu A., Inai Y., Hirabayashi T.: Effects of geometric structure in unsaturated aliphatic polyesters on their biodegradability. Polymer Journal, 33, 746-753 (2001).

https://doi.org/10.1295/polymj.33.746

[30] Stuart B. H.: Polymer analysis. Wiley, Chichester (2002).

[31] Farmer T. J., Castle R. L., Clark J. H., Macquarrie D. J.: Synthesis of unsaturated polyester resins from various bio-derived platform molecules. International Journal of Molecular Sciences, 16, 14912-14932 (2015). https://doi.org/10.3390/ijms160714912

[32] Dai J., Ma S., Liu X., Han L., Wu Y., Dai X., Zhu J.: Synthesis of bio-based unsaturated polyester resins and their application in waterborne UV-curable coatings. Progress in Organic Coatings, 78, 49-54 (2015). https://doi.org/10.1016/j.porgcoat.2014.10.007
[33] Jacobs W.: Resin systems. in 'Delaware composites design encyclopedia’ (eds.: Bader M. G., Smith W., Isham A. B., Rolston J. A., Metzner A. B.) Technomic Publishing, Lancaster, Vol 3, 15-84 (1990).

[34] Johnson K. G., Yang L. S.: Preparation, properties and applications of unsaturated polyesters. in 'Modern polyesters: Chemistry and technology of polyesters and copolyesters' (eds.: Scheirs J., Long T. E.) Wiley, Chichester, 697-713 (2003).

https://doi.org/10.1002/0470090685.ch21

[35] Rogers M. E., Long T. E.: Synthetic methods in stepgrowth polymers. Wiley, New Jersey (2003).

[36] Dholakiya B.: Unsaturated polyester resin for specialty applications. in 'Polyester' (ed.: Saleh H. E. M.) InTech, Rijeka (2012).

[37] Teramoto N., Ozeki M., Fujiwara I., Shibata M.: Crosslinking and biodegradation of poly(butylene succinate) prepolymers containing itaconic or maleic acid units in the main chain. Journal of Applied Polymer Science, 95, 1473-1480 (2005). https://doi.org/10.1002/app.21393

[38] Fink J. K.: Reactive polymers fundamentals and applications: A concise guide to industrial polymers. William Andrew Publishing, Norwich (2013).

[39] Noordover B. A. J., van Staalduinen V. G., Duchateau R., Koning C. E., van Benthem R. A. T. M., Mak M., Heise A., Frissen A. E., van Haveren J.: Co- and terpolyesters based on isosorbide and succinic acid for coating applications: Synthesis and characterization. Biomacromolecules, 7, 3406-3416 (2006).

https://doi.org/10.1021/bm060713v

[40] Lu S. X., Anseth K. S.: Photopolymerization of multilaminated poly(HEMA) hydrogels for controlled release. Journal of Controlled Release, 57, 291-300 (1999). https://doi.org/10.1016/s0168-3659(98)00125-4

[41] Yang Y. S., Lee L. J.: Microstructure formation in the cure of unsaturated polyester resins. Polymer, 29, 17931800 (1988). https://doi.org/10.1016/0032-3861(88)90393-X

[42] Smith K. E., Parks S. S., Hyjek M. A., Downey S. E., Gall K.: The effect of the glass transition temperature on the toughness of photopolymerizable (meth)acrylate networks under physiological conditions. Polymer, 50, 5112-5123 (2009). https://doi.org/10.1016/j.polymer.2009.08.040

[43] Melot D., Escaig B., Lefebvre J. M., Eustache R. P., Lauprêtre F.: Mechanical properties of unsaturated polyester resins in relation to their chemical structure. I. Secondary relaxations and local motions. Journal of Polymer Science Part B: Polymer Physics, 32, 249-260 (1994). https://doi.org/10.1002/polb.1994.090320206

[44] Cherian B., Thachil E. T.: Synthesis of unsaturated polyester resin - Effect of choice of reactants and their relative proportions. International Journal of Polymeric Materials and Polymeric Biomaterials, 53, 829-845 (2004). https://doi.org/10.1080/00914030490502364 